\title{
Essentials of Cyberspace Education for Online Students
}

Bahaudin G. Mujtaba, (Email: mujtaba@nova.edu), Nova Southeastern University Shruti Salghur, (Email : salghur2004@yahoo.com), Nova Southeastern University

\begin{abstract}
In the twenty first century, the development and advancement of the Internet Technology has remarkably transformed and redefined various fabric of human life, from individual communication to the way in which businesses conduct themselves. One of the more significant paradigm shifts has been in the field of education, particularly with the introduction and rapid growth of distance learning. Online education has afforded students, especially working adults, an opportunity to become involved in the learning process, bridging the gap that once existed between the busy lifestyles of working professionals and their goals of obtaining a University degree. Although there are many differences between the conventional modules of face-to-face and the online educational formats, both underscore the importance of learner participation and interaction that assist instructors in developing and initiating effective facilitation techniques to promote learning and retention among adult learners. This document outlines certain skills and nuances of online education and the essential skills that one requires for the successful completion of courses and programs. One of the most important aspects of online learning is communication, wherein online correspondence in the form of emailing, chatting and online discussions are critical when communicating with instructors, colleagues and administrations. Therefore, unlike other literature on cyberspace learning, this document provides a simple format on the essentials of online learning, chatting and emailing, without inserting too much academic literature, and acts as a manuscript for the "know-hows" of online education for prospective online students.
\end{abstract}

\section{DISTANCE LEARNING AND ONLINE PROGRAMS}

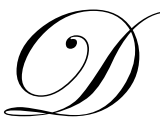

r. W. Edwards Deming once said, "Learning is not compulsory. Neither is survival." Therefore, adult learners make the fundamental choice to undertake classroom and/or online based education for the purposes of achieving their personal and professional goals. Malcolm Knowles, a pioneer in the field of adult learning, highlighted the many characteristics of adult learners. In essence, research suggests that adult students possess an extensive background of experiences and knowledge acquired through a history of work-related activities, family responsibilities and previous education, they are more autonomous, self-directed, goal-oriented and practical individuals that focus on lessons that are most relevant and useful to their work environment.

Online education is an educational format that enables an individual to complete a degree program (i.e. Bachelor, Masters, etc.) and/or certain courses online and requires the use of specific computer hardware and software technology, access to the Internet and requisite courseware (i.e. WebCT). In recent times, the term online education is synonymous to the concept of "distance education" since an individual can pursue online courses without having to be "physically present" in a designated location. The main component of online or distance education is the Internet (i.e. Internet-based learning) that can be utilized in various ways when delivering online courses. For one, the Internet technology can act as the primary mode of delivery via the means of asynchronous communication such as discussions, chatting and emails (i.e. Computer Conferencing). In addition, the Internet can act as a support mechanism for distance learning programs with the help of Computer Conferencing Medium. Third, the Internet can assist in virtually delivering all the courses of a degree program online (virtual courses). The H. Wayne Huizenga School of Business and Entrepreneurship of Nova Southeastern University (Fort Lauderdale, Florida) offers its 
students the distinct opportunity to either complete the requirements of an entire program online or diversify one's course structure by combining online and ground-based courses (i.e. hybrid curriculum).

Ironically, the traditional format and computer-based education are vastly similar in the sense they share parallel class structures and formats including similar grading criteria (i.e. participation, exams) and attitudes toward plagiarism. In addition, both formats require that their students closely follow the class syllabus and be on par with the pre-assigned readings and assignments and have unlimited administrative support. Table 1.1 displays the various attributes of both the aforementioned educational structures. As indicated, the two largely differ in their respective modes of delivery, wherein ground-based courses are "on-ground" and typically known as "face-to-face" learning whereas the other is "online-based" and relies on the computer conferencing medium. Guest speakers and office hours, for instance, are "virtual guests" and "virtual office hours" in online instruction and more over there is a greater dependence on email conversations, chat sessions and bulletin-board discussions (asynchronous and synchronous) in online education. The following part of the paper observes the popularity, growth and certain features of online education.

Table 1.1: Differences Between Face-To-Face and Online

\begin{tabular}{|l|l|l|}
\hline \multicolumn{2}{|c|}{ Face-To-Face } & \multicolumn{1}{|c|}{ Online } \\
\hline Similarities: & Courses not identified whether taken online or ground-based \\
\hline Transcripts & Participation and preparation accounted for in the grades \\
\hline Grading & Specific time period allotted for any class withdrawals or changes \\
\hline Withdrawal & Plagiarism can lead to academic probation and even expulsion \\
\hline Plagiarism & Transfers available based on department criteria and pre-determined conditions \\
\hline Credit Transfer & \multicolumn{2}{|l|}{} \\
\hline \multicolumn{3}{|l|}{} \\
\hline Differences: & $\begin{array}{l}\text { Classroom; Direct interaction with } \\
\text { professor and students }\end{array}$ & $\begin{array}{l}\text { Online interaction with professor and } \\
\text { students via different modes such as } \\
\text { scheduled chat sessions, bulletin boards } \\
\text { (discussion), online timed exams; use of } \\
\text { graphics, and visuals to present } \\
\text { materials }\end{array}$ \\
\hline Redes of Delivery & $\begin{array}{l}|c| \\
\text { Readings and Assignments }\end{array}$ & $\begin{array}{l}\text { Pre-assigned readings as noted in class } \\
\text { syllabus } \\
\text { syllabus }\end{array}$ \\
\hline Subject Matter Experts/Guests & "Classroom" guests & "Virtual" guests \\
\hline Access to Support & $\begin{array}{l}\text { Access to registration and administration } \\
\text { support "online" or via personal visits }\end{array}$ & $\begin{array}{l}\text { Access to registration and administration } \\
\text { support "online" }\end{array}$ \\
\hline Office Hours with Professor & "Walk-in" Office Hours & "Virtual" Office Hours \\
\hline
\end{tabular}

\section{The Popularity And Growth Of Online Education And Certain Features}

The flexibility and the convenience of online education have appealed to a wide and diverse demography especially working professionals and adults. In observing the nature and extent of online higher education in the U.S and based on the response of 1,100 colleges and Universities, the number of students taking at least one online course has increased from 1.6 million students in 2002-2003 to approximately 2 million in 2003-2004 (Allen \& Seaman, 2004; See Figure 1.1). The majority of the participating schools affirmed that many of their online "students were at least as satisfied as those (students) taking conventional face-to-face format" (Allen \& Seaman, 2004, p. 10). The high rate of satisfaction may be a reflection of the high quality and standards maintained within online-based learning and a result of quality instruction. 


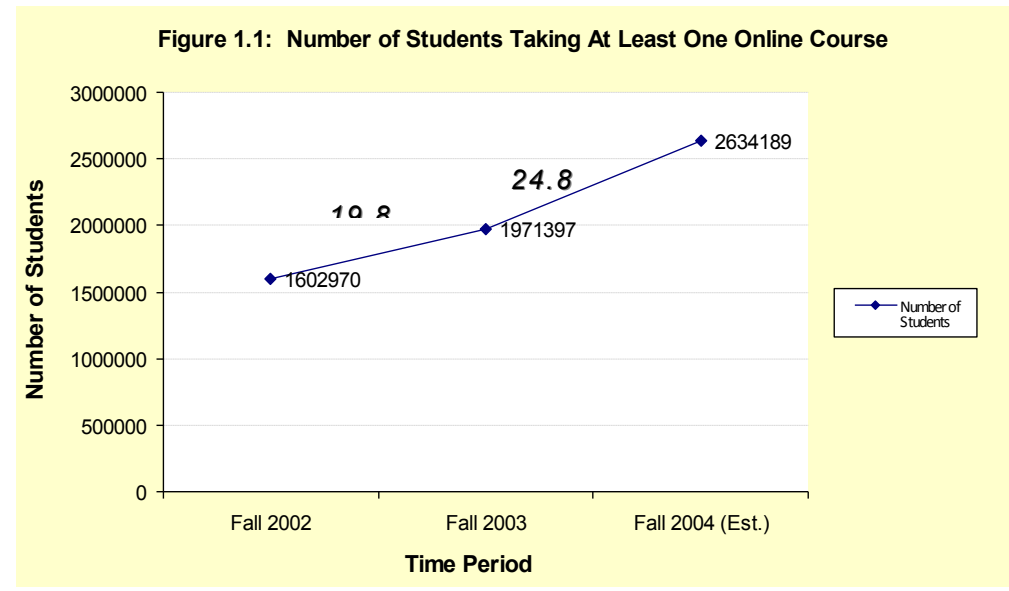

Source: Allen \& Seaman, 2004) - The Sloan Consortium

Instructors play a prominent role in the popularity and attitudes of online education and in the knowledge generation process. Often times, institutions with the distance learning option hire highly competent professors who are subject matter experts and who have had prior experience in the instruction of ground courses. This has helped universities sustain and maintain the consistency and quality of their online courses, especially for students that are making a transition from face-to-face to online education. Table 1.2 illustrates the various modes of online delivery and an array of tools that professors have used to enhance online-based learning. Many educators utilize a combination of colorful graphics, audio and video streams, and hypertext links to enhance student comprehension of course material. Instructors also directly communicate their course objectives with their students and administer the submission of course assignments, tests and exams. Although traditional educators have been apprehensive with the lack of "face-to-face" interaction that exists in the online format, research comparing student outcomes of online and classroom courses has shown that there is a strong learning equivalency that exists in both types of learning. The following section of the paper highlights certain aspects of online education that prospective students should consider.

Table 1.2: Online Modes of Delivery

\begin{tabular}{|l|l|}
\hline Print & E-text, textbooks, e-zines \\
\hline Video & Streaming video, video tape, satellite transmission, cable \\
\hline Audio & Streaming audio, audio tape \\
\hline Review and Exams & Electronic, interactive, paper \\
\hline Communication & $\begin{array}{l}\text { Asynchronous: } \\
\quad \text { email, listservs, threaded discussion, weblogs, forums } \\
\text { Synchronous: } \\
\text { o Chat, videoconferencing, teleconferencing }\end{array}$ \\
\hline
\end{tabular}

Source: Retrieved on 02, 24, 2005 from: http://www.worldwidelearn.com/elearning/elearning-types.htm

\section{KEY CONSIDERATIONS FOR PROSPECTIVE ONLINE STUDENTS}

\section{Program Cost}

When considering an online program, adult learners and students should take a relatively cautious approach in selecting their choice of online program. One should consider the accreditation status of schools to ensure the 
credibility and usefulness of the program and, certainly, the costs associated with the online degree program. The tuition costs of online programs vary based on the institution and the program; however, the costs of online programs are usually comparatively higher than that of face-to-face programs due to the high costs associated to the upkeep of online technology and courseware. A Masters of Business Administration (MBA) program, for instance, can range from $\$ 15,000$ to over $\$ 100,000$ depending on the school and the program curriculum. Therefore, making such a financial commitment would require a full understanding of the program curriculum, its relevance to one's future, the institution offering the program and the depth and the attributes of the program, including the online and on-campus resources available.

Students have various financial aid and scholarship options to reduce their cost burden. However, with the rise in number of students taking at least one online course from 19.8\% in 2002-2003 to 24.8\% in 2003-2004 (Allen \& Seaman, 2004) and an increase in the numbers of institutions offering the online option, educators foresee a reduction in the online tuition and costs (See Figure 1.1). In the South Florida region, there are over 30 different universities (including University of Florida, Nova Southeastern University and Florida Atlantic University, to name a few) offer students the option to pursue an online degree program. Given that the online education sector has become a highly competitive sector and a lucrative business opportunity, institutions are likely to reduce their costs to attract and retain their online student population. Along the same lines, to increase student retention, institutions are more likely to enhance their quality of online education by increasing their investments in their technology. In fact, many institutions have been expanding their programs to locations beyond their central campus to reach a wider demography and area. In addition, to assist students with their online endeavors, institutions have played a proactive role by appreciating the needs of their clientele. Universities offer a variety of tools, especially recommendations of computer hardware and software (i.e. courseware), online "help desks," toll-free assistance, etc. to help students make a smooth transition from the traditional to the online setting.

Online education offers a great extent of freedom and independence, which, in turn, suggests that a successful student would have the capability to maintain a level of self-discipline, exceptional management skills, communication techniques and a strong working knowledge of online technology. While instructors provide limited guidance and are involved in creating the ideal setting for a productive online learning environment, online students must play a prominent and active role in the knowledge generation process through regular online interaction with their instructor(s) and their colleagues every week. Such involvement is critical to learn, be able to utilize and retain the class material. In essence, students are encouraged to provide constructive feedback so that an instructor is aware of how to enhance a student's online learning experience. Overall, for the successful completion of online courses students should:

1. Assemble a list of various programs and institution offering their choice of programs that best matches their needs.

2. Determine a program's graduation requirements and anticipated graduation date, post-graduation employability rates, and the program's overall ranking.

3. Assess their personal learning styles, preferences and interests.

4. Have knowledge of their instructor's credentials and teaching techniques.

5. Gather additional information from interviews of school administrators, advisors and student services to become aware of the technical resources and assistance available for online students.

6. Physically visit the institution that offers their intended program in becoming familiar with the school's culture and the overall quality of the program.

There are certain skills that one must possess for the successful completion of online courses and/or programs. Among many, having a thorough understanding and knowledge of computer skills including Internet surfing, uploading and downloading documents and the use of online courseware (i.e. Web CT) are critical. The next section expands on the requisite skills that have been widely acknowledged as being useful for online programs and education. 


\section{REQUISITE SKILLS FOR ONLINE EDUCATION}

Online learning is seemingly ubiquitous in today's higher education system. There are a wide array of online programs and courses available to interested applicants and the successful completion of online courses requires the effective use of communication (chatting and email etiquette), research, technical, time management and reading skills (see Figure 1.2). More importantly, the communication aspect and the tools to facilitate online communication (online chatting and emails) are especially critical since the lack of face-to-face interaction is a much-debated aspect among students, administrators and instructors. Therefore, the alternatives to the face-to-face learning such as real-time chat sessions, email interaction and telephone conversations provide students an equal opportunity to develop the essential communicative relationship with their designated professors and peers. Hence, having an understanding of the communication tools and certain protocols are critical for online success.

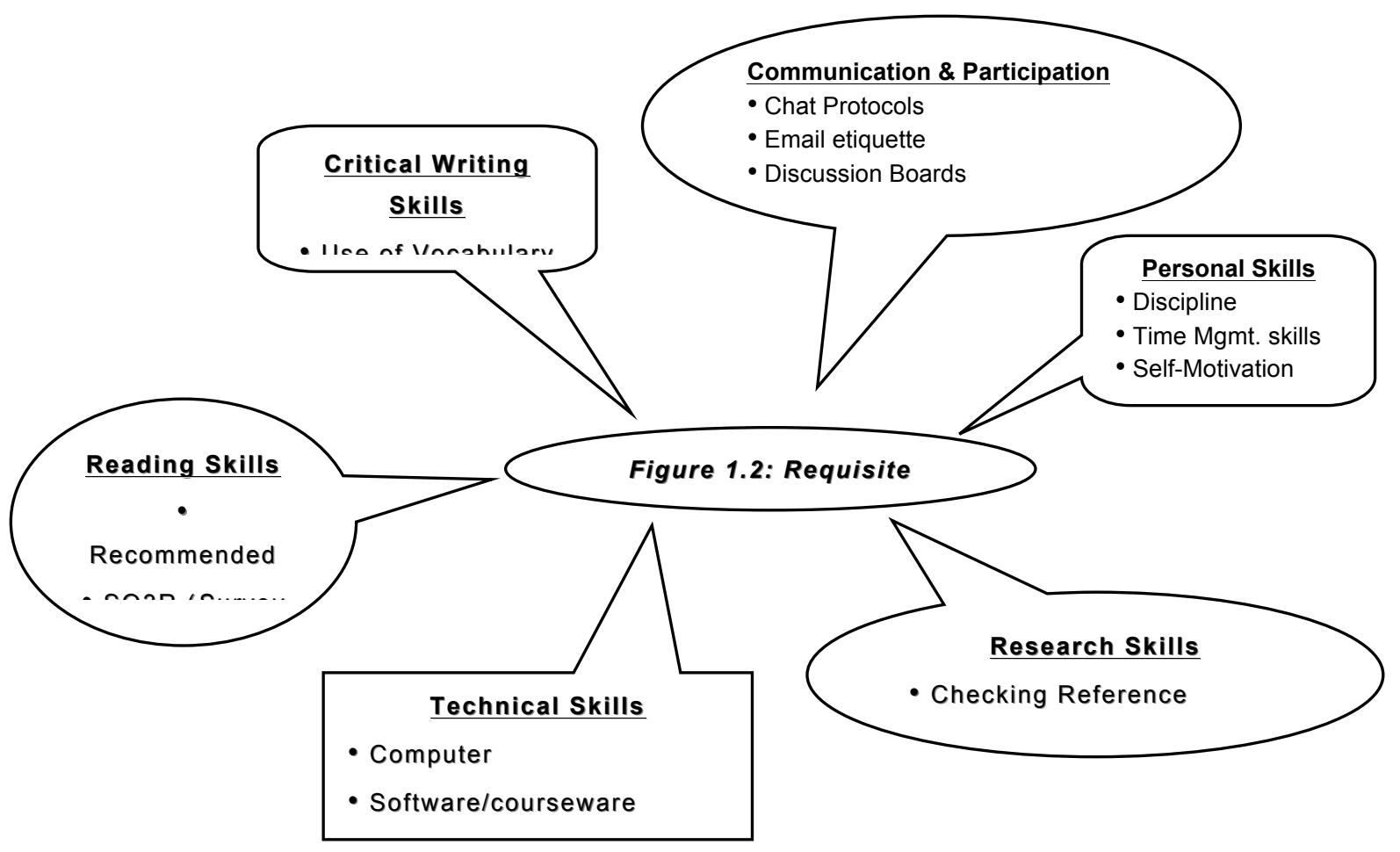

\section{Online Chatting}

Online chatting is one form of communication that is widely utilized in online learning. While most online courses are asynchronous, many educators hold synchronized chat sessions to assess learning needs and to ensure the steady progress of students. Online faculty members at Nova Southeastern University (NSU), for instance, have certain common rules for chatting that they relay to their students during the first week of classes. The following are some general chat rules that Dr. Bahaudin Mujtaba, professor international management at Nova Southeastern University, has incorporated and enforced in conducting online courses:

1. Discussions begin and end at scheduled times.

2. Pre-assigned readings complement the discussions.

3. Chat discussions consist of general topics or specific questions wherein students are required to actively participate and respond to the questions. In the case where questions posed to a specific individual, the student has 30 seconds to respond, while other members have the opportunity to comment and/or pose further questions for clarification purposes. 
4. To benefit from chat sessions, students should attend and qualitatively participate in each chat session and are encouraged to be both constructive and critical when responding to questions.

5. Students are encouraged to engage in discussion sessions on the bulletin board and the week's assigned topics without the instructor. Each individual has the opportunity to express one's opinions and thoughts. The chat-session transcripts are accessible by the instructor that uses it for grading and evaluation purposes.

6. In the case where students confront difficulties in computer connections and/or technical issues, they have the option to re-join and continue with the discussion session upon connection.

7. Students are highly encouraged to ask questions but with care, particularly when considering if the question should be posed publicly and/or privately.

8. Maintaining a sense of professionalism is critical and this includes paying close attention to the "tone" of the chat message, avoiding judgments, being cordial and respectful and avoiding the use of inappropriate and/or derogatory terms. All these help avoid unnecessary conflict.

9. At times when topics, which are not discussed during scheduled chat sessions, students have the option to use bulletin boards (newsgroups) to discuss issues and concerns, which allow for more time and research opportunity before the next scheduled chat session.

The latter designated rules on chat sessions act as a set of guidelines to assist students in understanding the basic chat specifications and expectations that create for a healthy learning environment for students. In addition to the "chat" tool, as listed above, asynchronous bulletin board discussions, newsgroup interactions and emails act as alternative forms and additional sources of interaction with the professors and fellow students. The next section looks at one of the most commonly used forms of communication, email and certain protocols that one must consider.

\section{Emails: Certain Protocols}

Email protocols act as guidelines that universities employ and implement to enable an acceptable form of electronic communication between students and professors. With the growing threat of viruses and hackers, many instructors are hesitant to open and/or respond to indistinguishable emails or files. Therefore, certain protocols are in place to ensure a level of security as well as increase the chances of receiving a timely response from an instructor. The following is a list of some email protocols, wherein students should:

1. Mention full name, specific subject title, the course, the date and a request for a response. Additional contact information such as "telephone" number is optional.

2. Include a subject line in every email message sets the tone and the purpose of the message.

3. Incorporate a brief, but clear message that expresses the intent of the email.

4. Avoid over-abbreviating and/or being overtly cryptic as this may result in greater ambiguity in the email message.

5. Use certain emotion/symbols when relaying emotions such as humor or sarcasm such as : - ) (smile) to avoid potential miscommunication.

6. Utilize lowercase letters than the use of uppercase letters, which often signifies screaming or shouting. Readability studies have shown that it takes less time to read all-lowercase messages versus an all-uppercase message. The use of asterisk to emphasize a certain word or phrase is a more acceptable form of expressing a message.

7. Proofread their work and check for spelling and grammatical errors.

8. Use caution when providing confidential information such as social security number, student identification number, credit card, etc.

9. Include the original text of the message as a reference point when responding to messages.

10. Be aware of sending emotionally charged messages as this may ultimately have severe repercussions on relationships.

11. Be considerate of people's privacy and therefore avoid the mass distribution of other email addresses. When sending an email message to a group of people it is courteous to list all the recipient email addresses in the Blind Carbon Copy (BCC) field. The Blind Carbon Copy field enables the intended recipient to get the message while ensuring the anonymity of other addresses. 
12. Delete prior trail of messages as they act as an inconvenience for the recipient who may have to scroll through a list of irrelevant messages and email addresses to read the actual email content.

13. Seek appropriate permission when relaying certain jokes and other information as this may lead to misinformation and misinterpretation of email content.

\section{ASYNCHRONOUS LEARNING ENVIRONMENT}

Today, we live in a "fast paced" society; hence, interacting in an asynchronous society has become a norm rather than an exception. The American Heritage ${ }^{\circledR}$ Dictionary of the English Language, Fourth Edition, defines asynchronous as the: "Lack of temporal concurrence; absence of synchronism." Previously, the American education system was premised on the concept that learning had to occur in a "synchronous" environment. Technology in the twenty first century has been critical in advancing the level of communication and interaction across international boundaries from commerce to achieving a quality online education. An individual from Istanbul, Turkey has opportunity to freely purchase goods from a Store in New York in the United States. Physical presence at a time and place is no longer a prerequisite for people to meet.

From an Education standpoint, an asynchronous learning environment enables both the instructor and the student to facilitate their own schedule that best fits their needs and demands of everyday life. Learning can, therefore, be structured to meet one's needs. Given that people possess different qualities with varying learning and study styles, one may perform at one's best at 6:00am, whereas another at 10:00pm. Therefore, an asynchronous learning environment allows for an individual to develop a unique and personal agenda. Therefore, it is safe to deduce that in today's environment the absence of synchronism is not necessarily a detriment, but instead a benefit in education.

There are many benefits of interacting in an asynchronous online environment. For one, the independence and the ability to access online courses based on student's convenience are important and popular elements of online learning. The flexibility, customizability and mobility of the course structures allow working professionals to follow their daily routines and pre-scheduled activities while obtaining a degree. Second, students have the opportunity to refer back to previous postings, interactions and other course-related communications. A third such benefit, which may not be as obvious, is the opportunity that certain students, who are inhibited to speak in traditional class room setting receive the opportunity to comfortably discuss their opinions online. As a result, online education platform helps create a more participative and interactive learning environment for students of all personalities and traits. This also enables students to not just learn from the instructor, but from their peers. Fourth, online learning also requires more student involvement since quality participation is a large part of an instructor's grading criteria. Lastly, students have the "space" for personal reflection on class comments and/or notes.

One of the most prominent and much debated aspects of online education is the lack of "face-to-face" interaction, which is critical in one's development of inter-personal and public speaking skills. Given that students and instructors are geographically dispersed, they are isolated from each other. Another such limitation is how an instructor can ensure student development and participation without the "physical" contact. Since the first author is a certified "Steven Covey" trainer for the "Seven Habits of Highly Effective People" workshops, he agrees with Covey's Time Management quadrants which suggest that it is essential to first focus on and complete what is "important and urgent" followed by performing activities that are "important but not urgent" while minimizing the "urgent and important category" and maximizing time in the "important but not urgent" quadrant.

The limitations of face-to-face interaction can be resolved by encouraging students and participants to socialize in their work environment to consciously help build public speaking skills. In the online classroom setting, encouraging students to state a brief biography of oneself acts as a good starting point. In addition, instructors should make students aware of the many benefits of online learning including the development of essential skills such as building self-discipline and the impact online classes have in one's future course. Other important suggestions include a) compiling a "to do" list every day/week/month; b) maintain a planner that helps one document the plan and course of action; and c) exercising good judgment, while remaining flexible and focused on the important activities 
and life lessons that contribute to fulfilling one's life goals and objectives. Overall, universal principles of time management that are conveyed to on-ground students are applicable to online learners.

In the world of distance learning, time is no longer a hindrance to education as instructors and students do not have to simultaneously and physically interact with each other. In his book, Freedom to Learn, Carl Rogers (1969), provides certain distinct "Guidelines for Facilitation." Although his guidelines may seem outdated since it was written in 1969, they continue to be applicable in today's online context. Although the instructional process continues to rely on the principle that: "The teacher (or facilitator) takes the initiative in sharing himself/herself with the group- feelings as well as thoughts- in ways that neither demand nor impose, but represent simply a personal sharing which the student may take or leave", such standards can be applied to the twenty first century's online environment. From an instructor's point of view, one can customize the lessons or tutoring methods based on an individual's needs, which is often cumbersome in a class-room environment. A useful facilitation tactic is to encourage students to have healthy dialogues and debates amongst each other and/or in corporate arenas. To ensure that students are fully aware of class expectations, teachers should have "written documents" which helps clear any ambiguity that sometimes exists in verbal communication. As a human resource specialist and trainer, the first author is personally aware of the importance of written communication which often takes precedence over "oral" agreements in many legal cases, which is important to bear in mind.

Thus far, the above literature helps analyze some of the essential aspects of online learning from various perspectives. The following section provides a list of essential tools, resources and features of online education that will assist in the online endeavors of both educators and learners.

\section{ESSENTIALS FOR ONLINE STUDENTS}

As online education continues to take shape, especially with technological advancements, this mode of education continues to be subject of much debate. As a result, students and learners are forced to swift through mounts of information and differentiate between myths and facts. The following highlights some of the many myths regarding online education.

Myth 1: Employers frown upon online degrees and have a preference for traditional ground based programs.

The need for convenience in education stems from the demand of working adults who have a need to access education "any time," "any place" without compromising quality. To meet this demand, more and more traditional based programs are offering online courses. By leveraging technology to scale education, Institutions not only meet the growing demand but have the opportunity to add to their revenue generation activities.

Employers generally look for degrees from credible, well-recognized accredited schools on a candidate's resume in addition to a combination of hard and soft skills. How does a student go about selecting a quality education program? It is the responsibility of students to ensure that the school has the proper accreditation and that their program is a good fit for their aspirations and goals.

\section{A. Accreditation:}

Institutional accreditation by a regional accrediting body (such as SACS) plays a critical role. A great resource and reference is the Council for Higher Education Accreditation (www.chea.org) that lists institutions and their respective accreditation. Bear in mind there are nationally and regionally accredited institutions. There are also programmatic accreditations that are specific to individual Programs such as APA for Psychology, AACSB or IACBE for Business, and CCNA for nursing programs, to name a few.

It goes without saying that a student should conduct thorough research and inquire with current and prospective employers their requirements regarding schools and accreditation preferences. Along with questioning a Program's accreditation, inquiring about Program outcomes, graduation rates, historical trends, and a list of employers that have hired alumnus to name a few. 


\section{B. Program Fit:}

There are research materials and self-assessments available for students to help determine a Program that fits their needs. A great resource is the Bureau of Labor Statistics (www.bls.gov) that provides growth rates, career path information and salary trends.

Technology has enabled certain Programs to be completed entirely online. Some are hybrid based whereby students can combine traditional campus based courses with online components. Many courses such as the hard-sciences like chemistry and anatomy are mostly ground based due to a lab component that requires students to physically perform experiments.

Again, not all Programs can and should be completed online. For instance, if a student is looking to become a Nurse, an entirely online program would seem peculiar as it requires hands-on experience in laboratories and with patients.

If a student is interested more so along the lines of Business, for instance, it is likely that they can complete an entire program online from an accredited institution. At Nova Southeastern University, which is a fully accredited institution, a student at the Huizenga College of Business and Entrepreneurship can, in fact, complete an MBA program entirely online.

\section{Myth 2: Online courses are not structured.}

This myth is far from the truth. Although there is a widely shared perception that online courses can be completed anywhere anytime, it still has a structure and requires tremendous discipline. Just as it is with campus-based programs, online courses have the syllabus where expectations of the course is clearly described. Students are required to read textbooks, cases and journal articles just as they would if they were attending a class on campus and are required to complete all the necessary assignments.

The rule of thumb generally is that each course can require anywhere from 9 to 15 hours per week that could comprise of reading assignments, discussion board participation, writing papers, case study assessments, completing tests and exams, and working with other teammates on specific projects. This, again, is no different than the traditional courses that have a similar structure. The only difference is how the courses are delivered.

Myth 3: Professors are not real and are not accessible.

Real instructors teach online courses. In many cases, the same professors teach both online and ground based courses at the Institution. They are accessible through various communication modes including email, virtual office hours and phone calls.

In fact, technology has offered innovative ways to enhance student-teacher-peer engagement. Live lectures and video conferencing have become the norm. In fact, students can access recorded sessions or lectures, which is an added benefit to online education in the event a student needs additional clarification on the materials or expectations for each module or forum.

Myth 4: Credits earned through online courses cannot be transferred or is not recognized.

Such nonfactual blanked statements could do more harm than justice. Transfer of courses is vastly dependent on the institution a student is seeking to attend or transfer into. It is advisable for the student to work with University officials to determine transfer eligibility of courses.

Myth 5: A student doesn't have the same support system as campus based students. 
Any credible institution should and would provide all students access to quality support services such as Career Services, Tutoring, and Student Engagement Programs irrespective of the way they might attend a course. This is true at Nova Southeastern University wherein an online student can access the resources that a traditional student has. Career Services, for instance, put together virtual career fairs and important webinars on interviewing techniques and resume development. Students can also receive one-on-one advising through tools such as Skype. Online tutoring have become common place as well to help with student success.

Myth 6: Online Programs are less expensive than traditional campus programs.

Online program costs vary by institution and by program. In some cases, online programs may cost more than their traditional counterparts. Certain fees such as technology costs are tagged on to the cost per credit hour. It is worth asking about any hidden fees and costs. Periodically, based on the institution policy, costs can increase, not to mention the costs of books, simulations, and other assessment applications that might be required for some courses.

Christ and Ganey's (2003) book on the "100 Things Every Online Student Ought to Know," (Cambridge Stratford Study Skills Institute) serves as a basic guide and reference tool for students considering online education. The book addresses some foundational aspects of online education that a first time learner might find helpful. It also helps to de-mythify some of the myths that have been addressed in this article.

It is important to note that although the option for online education does exist, it may not be the best fit for all. But certainly having this modality of education as a choice, presents adults with extremely busy schedules an opportunity to achieve and pursue their education goals. It is without a doubt that online education is here to stay that will continue to advance exponentially in the coming years and decades.

The following facts and concepts are emphasized by most authors and educational experts for adult students who are considering online education.

1. Since learning and mastering of competencies are supposed to be exactly the same for both online and traditional course formats, students now have the option to complete an entire degree program online or may choose to combine certain online subjects with ground courses through hybrid curriculums. The flexibility, accessibility, and convenience of online educational programs tend to appeal to a large and diverse demography, especially working adults who travel as part of their jobs and those who are time-impoverished.

2. Online courses can be fully "asynchronous" wherein students can access online course materials based on their availability, convenience and schedule. Or, these courses can have synchronous requirements where communication between participants and the instructors is coordinated and occurs in real-time over the course of the semester. Synchronized chat sessions would require students to be present at a specific time at a designated discussion forum or chat room as determined by the University or the Platform in which the online course is facilitated.

3. Students in online courses tend to work individually and in teams with people across regions and continents. As such, online students will have the opportunity to network with a diverse group of people from varying backgrounds and cultures.

4. An online student's success is determined by his/her level of participation, interaction and contribution on the discussion boards. Of course, communication should not be limited just to the discussion boards alone. It is very important that online students interact with others in the class as well as those who have recently completed a specific course or the program. A variety of online tools are available for students' use to communicate with peers, instructors and others that makes the online experience very interactive and an ideal opportunity for learning from multiple sources.

5. Communicate properly by proof-reading your postings and emails prior to sending it. It is a good idea to keep a log of all emails and postings in a Word file for each course as this makes it easier to re-read your thoughts for editing and record keeping. Proofreading of your postings and emails should include checking for 
spelling and grammatical errors. Email communications should be complete, addressed properly and must have a professional tone.

6. Following directions carefully is essential when completing course assignment as they clearly outline the instructor's expectations and requirements. Try to keep track of assignments due dates and complete them before the deadline. Most of the online course readings and assignments can be completed offline hence it is essential that a student maintains a course folder that contains relevant resources and materials.

7. The library resources are available to all students, regardless of their modality. Various institutions have libraries as well as learning support centers and bookstores that have an assortment of books, journal articles, and how-to-study guides that are helpful to a student taking online courses. Make good use of such resources as part of your education journey.

8. There is no need to allow technical difficulties to stress you or waste your time. Most institutions have a "help desk" that provide technical (computer) assistance. Students should make note of important website links, phone numbers and contact information to receive technical support when you need it. Many institutions have operators that can guide you through phone calls or synchronized chatrooms in real-time. Often, you can even contact your professors in real time. A "virtual office" wherein online faculty members have allotted set office hours at which time students have the opportunity to address queries and issues. Many instructors host virtual office times for live chat and or synchronous communication.

9. Online students must be self-disciplined and highly proactive. As an online student, you must foster a level of self-discipline, time-management, communication and organization skills that will keep you successfully moving forward. Maintain the required motivation to be an independent self-learner.

\section{SURVEY OF ONLINE STUDENTS AT THE HUIZENGA SCHOOL}

The H. Wayne Huizenga School of Business and Entrepreneurship (Huizenga School) of Nova Southeastern University (NSU) has been offering graduate programs in the fields of business administration through various distance delivery modes for the past thirty years. In the late 1990s, the Huizenga School established online programs, where students could attend all of their courses using the online platform known as e-University with blackboard technologies. While there are many different delivery methods, each format achieves the same outcomes and uses the same textbooks to achieve the stated learning objectives and oftentimes uses the same faculty to teach in different modalities. Each program also surveys and assesses its current students as well as its alumni to determine the effectiveness of its programs.

There were a total of 987 students enrolled in the Huizenga School's online graduate business courses during the spring term of 2004. There were 82 online sections of various courses taught through e-University by various fulltime and part-time faculty members. An electronic survey was sent to all students enrolled. Over 229 students completed the surveys but only 229 surveys were fully completed and used for the analysis providing a return rate of $23.2 \%$. The demographics of respondents vary greatly by gender, age, and location since most of the students are working adults and live in different locations within the United States and foreign countries such as Jamaica, Korea, Bahamas, Kenya, etc.. While students have a choice of taking either online or onground courses to complete their masters programs, all student in the master of business administration program are required to complete the "GMP5014-Information Technology Applications in Management Decisions" online since it is only offered in this modality. Students are required to complete the course during their first few semesters as it is partially designed to familiarize them with the basics of information technology and online research. The respondents, as can be seen from Table 1.3, were mostly from the masters of business administration program taking classes during the spring term. 
Table 1.3- Online Program Enrollment

\begin{tabular}{|l|c|c|}
\hline Business Administration & 165 & $72 \%$ \\
\hline International Business Administration & 23 & $10 \%$ \\
\hline Human Resource Management & 25 & $11 \%$ \\
\hline Public Administration & 9 & $4 \%$ \\
\hline Leadership & 3 & $1 \%$ \\
\hline Master's of Accounting & 2 & $1 \%$ \\
\hline e-MACC & 1 & $0 \%$ \\
\hline Master of Taxation & 1 & $0 \%$ \\
\hline Total & $\mathbf{2 2 9}$ & $\mathbf{1 0 0 \%}$ \\
\hline
\end{tabular}

About 53\% (121 students) of the respondents are completing all of their courses online while 47\% (108) are taking online courses in addition to the onground. Most of these online students are accessing classroom material from home $(59 \%)$ and $3 \%$ of students only have access to the online classroom from their offices as demonstrated in Figure 1.3. In 2001, 84\% of the respondents stated that they accessed online classes from home (Mujtaba, 2004). While $38 \%$ of students are able to access online classes both from home and from their office locations in 2004 , only $11 \%$ said they could do this in 2001. Apparently, more working adults are now able to get school work done at the office in 2004 than three years ago.

Over $95 \%$ of online students stated that cable modem or DSL connections are available in their areas and over $66 \%$ of the respondents are using them. In 2001, survey of online students in the MBA program of Huizenga School showed that only $76 \%$ had cable modem or DSL available and $46 \%$ were using them (Mujtaba, 2001). Today, $25 \%$ of the respondents are using X28K-56K modems to connect to the class and, according to Mujtaba this number was $46 \%$ three years ago.

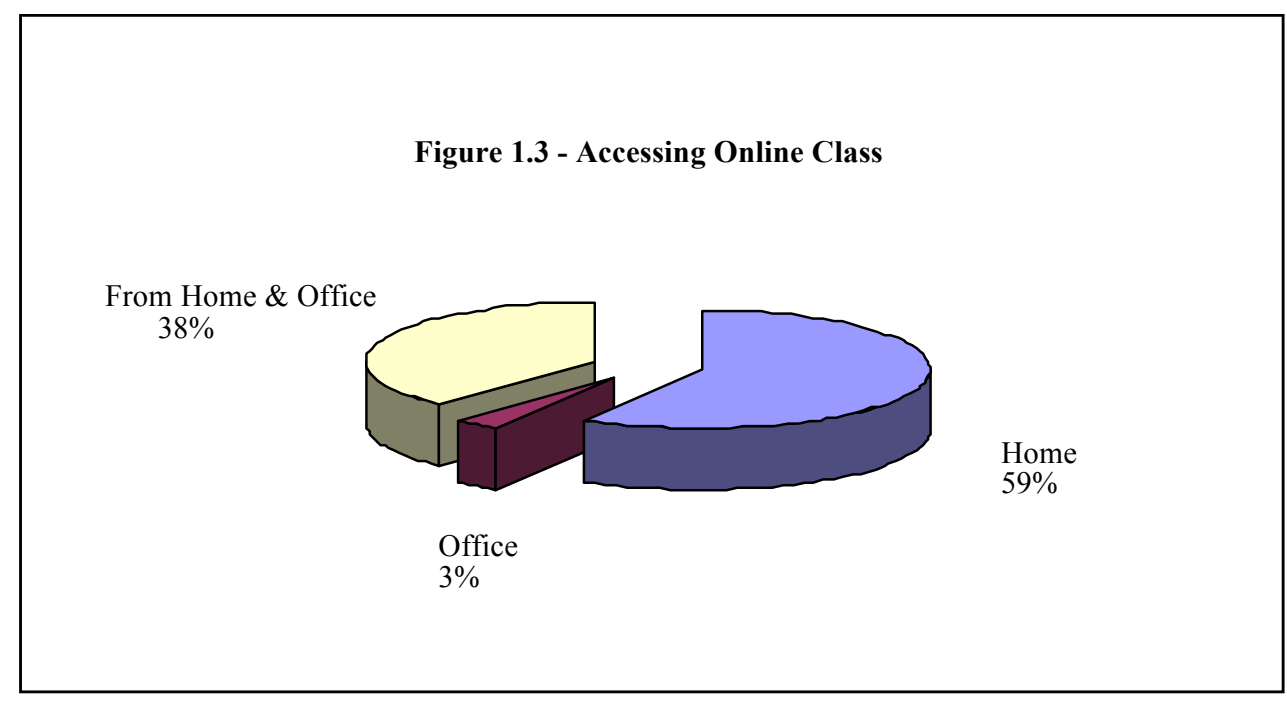

Majority of the respondents, as shown on Table 1.4, have the basic tools such as speakers, microphones, CDRom Drives, Windows 2000, and Microsoft Office. Apparently most of the students own the basic tools for having synchronized chat sessions. About $70 \%$ of these students owned Windows 2000 which means some people are still using older versions or other software. 
Table 1.4- Software Ownership

\begin{tabular}{|l|c|c|c|c|c|}
\hline $\begin{array}{l}\text { Software or Tools } \\
\text { Owned by Students }\end{array}$ & Speakers & Microphone & $\begin{array}{c}\text { CD Rom } \\
\text { Drive }\end{array}$ & $\begin{array}{c}\text { Windows } \\
\mathbf{2 0 0 0}\end{array}$ & $\begin{array}{c}\text { Microsoft } \\
\text { Office 2000 }\end{array}$ \\
\hline Students & 220 & 160 & 224 & 160 & 191 \\
\hline Percentage & $96 \%$ & $70 \%$ & $98 \%$ & $70 \%$ & $83 \%$ \\
\hline
\end{tabular}

One of the questions asked the following information: "On a scale of 1 to 5 ( 5 being the highest) what is your level of satisfaction with the technology used in the online programs (i.e. text-based chat sessions, bulletin board, course resources to include Power-Point presentations, lecture notes, etc.)." On the satisfaction scale of 1 to 5 for this question, over $82 \%$ ( $7 \%$ down from the $89 \%$ in 2001 ) of the respondents rated the technology used in the online program as 4 or 5 signifying above average level of satisfaction. About $13 \%$ of the respondents marked 3 signifying average satisfaction with $5 \%$ of the respondents providing a rating of 2 or below showing a less than average level of satisfaction with the technology used in the online courses.

On the satisfaction scale of 1 to 5 (five being most satisfied), over $82 \%$ of the respondents rated the online program as 4 or 5 signifying above average level of satisfaction. About $16 \%$ of the respondents marked 3 signifying average satisfaction with $2 \%$ of the respondents providing a rating of 2 or below showing a less than average level of satisfaction. Most students seem to have enjoyed their online experience in the masters of business programs. In another questions, students were asked "Have you ever taken an online course using the WebCT platform?" to see how many of them were already familiar with this platform from their previous experiences. Only $26 \%$ of them had taken a WebCT course before and $74 \%$ had never used WebCT platform in their educational programs. Reviewing the information from the 229 respondents at the Huizenga School's eMBA Program highlights several points with regard to the satisfaction of online students with the program and how the classes are facilitated. Students seemed to have been satisfied with their online courses and many of them wanted more interaction opportunities with the faculty and their peers through video or voice chatting software in the class bulletin board. It is no wonder that students like online classes. In online classes, students tend to see material that they may not always get in on-ground classes. For example, during February $24^{\text {th }} 2005$ in the first author's class, a working online student posted a very thoughtprovoking complaint letter from a bank customer that made all students think and interact about the customer's perspective. The course's title is "Delivering Superior Customer Value" and this letter was an excellent contribution for discussion (to read the letter, see Appendix: A Bank Complaint Letter). Such discussions about the real world challenges provide excitement and motivation for student contributions that in most cases lead to learning.

\section{SUMMARY}

No longer is one restricted to delaying one's higher education dreams due to a busy work schedule, a peripatetic lifestyle, or distance because Internet Technology has made obtaining a degree a reality with unlimited possibilities. Yet, making a transition from the traditional face-to-face format into the conventional mode may seem challenging. While online and distance learning education share similar characteristics, it has also introduced new components that has elevated the standards of education, making online learning highly marketable and appealing to a large and diverse demography, particularly among working professionals. The flexibility cyberspace education allows students and adults to study at home, the options it provides students in choosing to complete a program entirely online or via a mixture of online and on-ground courses (hybrid), the opportunity of obtaining a quality degree program and education as a result of highly-qualified and competent professors, and the increasing investment that colleges have made in online education nationwide reflects the very nature and the course of online education in the future.

\section{REFERENCES}

1. Allen, I.E. \& Seaman, J. (2004). "Entering the Mainstream: The Quality and Extent of Online Education in the United States - 2003 \& 2004". The Sloan Consortium - Sloan Center for Online Education. Retrieved December 26, 2004 from http://www.sloan-c.org/resources/entering_mainstream.pdf. 
2. Boyd, Drick (2004). "The Characteristics of Successful Online Students". New Horizons in Adult Education. Volume 18, Number 2, Spring.

3. Christ, F.L. \& Ganey, R. L. (2003). 100 Things Every Online Student Ought to Know. Cambridge Stratford Study Skills Institute, Williamsville, NY.

4. $\quad$ Eastmond, D. (1998). "Adult learners and Internet-based distance education". New Directions for Adult and Continuing Education, 78, pgs. 33-41.

5. Hamilton, Jennifer (2004). "Grades, Goals and GMAT Scores Factors in MBA Success". South Florida Business Journal: Guide to Education. July 16, 2004.

6. Henke, H. \& Russum, J. (2000). "Factors influencing attrition rates in a corporate distance education program". Education at a distance, 14 (11), Article 03. Retrieved July 25, 2001 from http://www.usdla.org/ ED_magazine/illuminactive/ NOV00_Issue/ story03.htm.

7. Howard Community College (2001). "Characteristics of Successful Online Students". Retrieved August 9, 2001 at http://www.howardcc.edu/online/ requir_courseofferings.htm.

8. Marquand, Barbara (2004). “Ask Questions before Heading to Graduate School”. South Florida Business Journal: Guide to Education. July 16, 2004.

9. Mujtaba, B., (2004). "Survey of Online Students at the H. Wayne Huizenga School of Business and Entrepreneurship of Nova Southeastern University". Presentation at the International Assembly for Collegiate Business Education (IACBE) Regional Conference. Wednesday, November 10, 2004. Orlando, FL.

10. Mujtaba, B., (2004). "What Do Online Students Need and Want from their Masters of Business Administration Program at the School of Business and Entrepreneurship?" International Applied Business and Economic Research Conference (IBER) Proceedings. October 4-8; Las Vegas, NV.

11. Mujtaba, B. \& Mujtaba, L. (February 2004). "Creating a Healthy Learning Environment for Student Success in the Classroom". The Internet TESL Journal. Vol. X, No. 2. URL link: http://iteslj.org/ or: http://iteslj.org /Articles/Mujtaba-Environment.html.

12. Mujtaba, B.; Preziosi, R.; \& Mujtaba, L. (April 2004). “Adult Learning, Assessment, and the Extraordinary Teacher". Journal of College Teaching and Learning. Volume 1, Number 4, pgs 29-37.

13. Mujtaba, B. \& Mujtaba, L. (March 2004). "Diversity Awareness and Management in Adult Education". Journal of College Teaching and Learning. Volume 1, Number 3. pgs. 65-75.

14. Mujtaba, B. (2001). "What Do Online Students Need and Want from their Masters of Business Administration Program at the School of Business and Entrepreneurship?" Report No: HS09-30-01. Retrieved on September 6, 2004 from the Huizenga School's website at URL: http://www.huizenga. nova.edu/about/research_reports.cfm.

15. Salghur, S. and Mujtaba, B. (2005). "What Online Students Should Know: Essential Cyberspace Skills for Chatting, Emailing and Learning”. College Teaching and Learning Conference Proceedings. January 3-7. "Best Paper" winner!

\section{APPENDIX}

\section{A Bank Complaint Letter}

The following is an actual letter that was sent to a bank by a 96 year-old woman:

To whom it may concern:

I am writing to thank you for bouncing my check with which I endeavored to pay my plumber last month. By my calculations, three nanoseconds must have elapsed between his depositing the check and the arrival in my account of the funds needed to honor it. I refer, of course, to the automatic monthly transfer of funds from my modest savings account, an arrangement, which, I admit, has been in place for only thirty-one years. You are to be commended for seizing that brief window of opportunity, and also for debiting my account $\$ 30$ by way of penalty for the inconvenience caused to your bank. My thankfulness springs from the manner in which this incident has caused me to rethink my errant financial ways.

I noticed that whereas I personally attend to your telephone calls and letters, when I try to contact you, I am confronted by the impersonal, overcharging, pre-recorded, faceless entity, which your bank has recently become. From now on I, like you, 
choose only to deal with a flesh-and-blood person. My mortgage and loan repayments will therefore and hereafter no longer be automatic, but will arrive at your bank, by check, addressed personally and confidentially to an employee at your bank whom you must nominate. Be aware that it is an offense under the Postal Act for any other person to open such an envelope. Please find attached, an Application Contact Status form, which I require your chosen employee to complete. I am sorry it runs to eight pages, but in order that I know as much about him or her as your bank knows about me, there is no alternative. Please note that a Notary Public must countersign all copies of his or her medical history, and the mandatory details of his/her financial situation (income, debts, assets and liabilities) must be accompanied by documented proof.

In due course, I will issue your employee with a PIN number, which he/she must quote in dealings with me. I regret that it cannot be shorter than 28 digits but, again, I have modeled it on the number of button presses required of me to access my account balance on your phone bank service. As they say, imitation is the sincerest form of flattery. Please allow me to level the playing field even further. When you call me, you will now have a menu of options on my new voice mail system to choose from. Please press the buttons as follows:

1. To make an appointment to see me.

2. To query a missing payment.

3. To transfer the call to my living room in case I am there.

4. To transfer the call to my bedroom in case I am sleeping.

5. To transfer the call to my toilet in case I am attending to nature.

6. To transfer the call to my mobile phone if I am not at home.

7. To leave a message on my computer, a password to access my computer is required. Password will be communicated to you at a later date to the Authorized Contact.

8. May I wish you a happy, if ever so slightly less prosperous, New Year?

Your Humble Client,

Remember: a 96-year old woman wrote this letter. 


\section{NOTES}

